\title{
Earthquake Early Warning in Japan: Warning the General Public and Future Prospects
}

\section{Osamu Kamigaichi, ${ }^{2}$ Makoto Saito, ${ }_{1}^{1}$ Keiji Doi, ${ }^{1}$ Toshiyuki Matsumori, Shin'ya Tsukada, ${ }^{4}$ Kiyoshi Takeda, ${ }^{1}$ Toshihiro Shimoyama, ${ }^{1}$ Kouji Nakamura, ${ }^{3}$ Masashi Kiyomoto, ${ }^{1}$ and Yukihiro Watanabe ${ }^{1}$}

\section{INTRODUCTION}

The earthquake early warning (EEW) information provided by the Japan Meteorological Agency (JMA) is designed to enable public officials, key safety personnel, and the general public to take advance countermeasures against the effects of earthquake strong motion. The goal of the early warning system is to provide the maximum expected seismic intensity and the earliest $S$-wave arrival time in each subprefectural area (about a quarter to a third of one prefecture) before the strong motion arrival. For the system to be effective, it is essential that JMA publicize the principle and purpose of the warning messages, the technical limits of EEW, and the proper actions to be taken when a warning is received. This is particularly important given the very short warning times (a few to a few tens of seconds) so that EEW can be used effectively without causing unnecessary confusion. In this article we outline the design of the EEW system in Japan and the necessary preparatory process to start providing EEW information to the general public, summarize the performance of the system since it was launched nationwide in October 2007, and discuss future prospects for the system.

\section{DESIGN OF THE EEW SYSTEM}

The parameters that the EEW must determine are the estimated origin time, the hypocenter location, the magnitude of the earthquake, the expected maximum seismic intensity (in the JMA intensity scale, http://www.jma.go.jp/jma/en/ Activities/earthquake.html\#S_I), and earliest arrival time (in seconds) of the strong motion for each subprefectural area.

In Japan, seismic intensity has been recorded by instruments designed specifically for this task (called "seismic intensity meters") since 1996. Seismic intensity meters observe seismic intensity at representative sites for the purposes of disaster mitigation (i.e., in the middle of populated areas); the data they

\footnotetext{
1. Japan Meteorological Agency, Tokyo, Japan

2. Sapporo District Meteorological Observatory, Sapporo, Japan

3. Sendai District Meteorological Observatory, Sendai, Japan

4. Earthquake Research Institute, Univ. of Tokyo, Tokyo, Japan
}

collect are not used for hypocenter and magnitude calculation. Seismic intensity is calculated from the maximum amplitude of the acceleration after a filter with $(1 / f)^{1 / 2}$ amplitude response is applied in the frequency range from 0.5 to $10 \mathrm{~Hz}$ (JMA 1996). Physically, seismic intensity is proportional to the logarithm of maximum kinematic energy flow into the observation site per unit time. JMA has been issuing seismic intensity reports on the maximum seismic intensity distribution in each subprefectural area within two minutes after the earthquake occurrence when seismic intensity of 1 or over (in JMA scale) is observed. More detailed information (seismic intensity at each observation site) promptly follows this report. Although these are "post-disaster" reports, they have been used as trigger information to start emergency responses such as directing rescue resources to an area where strong motion was observed. To integrate strong motion disaster mitigation, EEW was developed to enable countermeasures in advance of the strong motion arrival. For EEW, seismic intensities are evaluated at about 4,000 seismic intensity meter installation sites throughout Japan. Estimation of the seismic intensity has three steps: 1) estimation of hypocenter, 2) estimation of magnitude, and 3) estimation of seismic intensity. The third step is itself composed of three steps: 1 ) estimation of the maximum velocity amplitude on engineering bedrock ( $\mathrm{Si}$ and Midorikawa 1999), 2) multiplication by the amplification coefficient to account for the surface layer (Matsuoka and Midorikawa 1994), and 3) conversion from velocity to seismic intensity (Midorikawa $e t$ al. 1999).

The hypocenter is the starting point of the rupture and is fixed at the time the rupture starts. Whether the final size of the earthquake, i.e., the magnitude, is predictable at the starting time of the rupture is controversial (e.g., Iio et al. 1999; Nakatani et al. 2000; Mori and Kanamori 1996). Furthermore, a method that is applicable in the real-time processing environment to forecast the final size of the earthquake so that seismic intensity can be estimated to a socially acceptable precision has not been developed. Therefore, JMA does not "forecast" the final size of the earthquake by using the onset part of the seismic waveform. Instead, the growth of the rupture is monitored using the maximum amplitude in real time. To provide the 


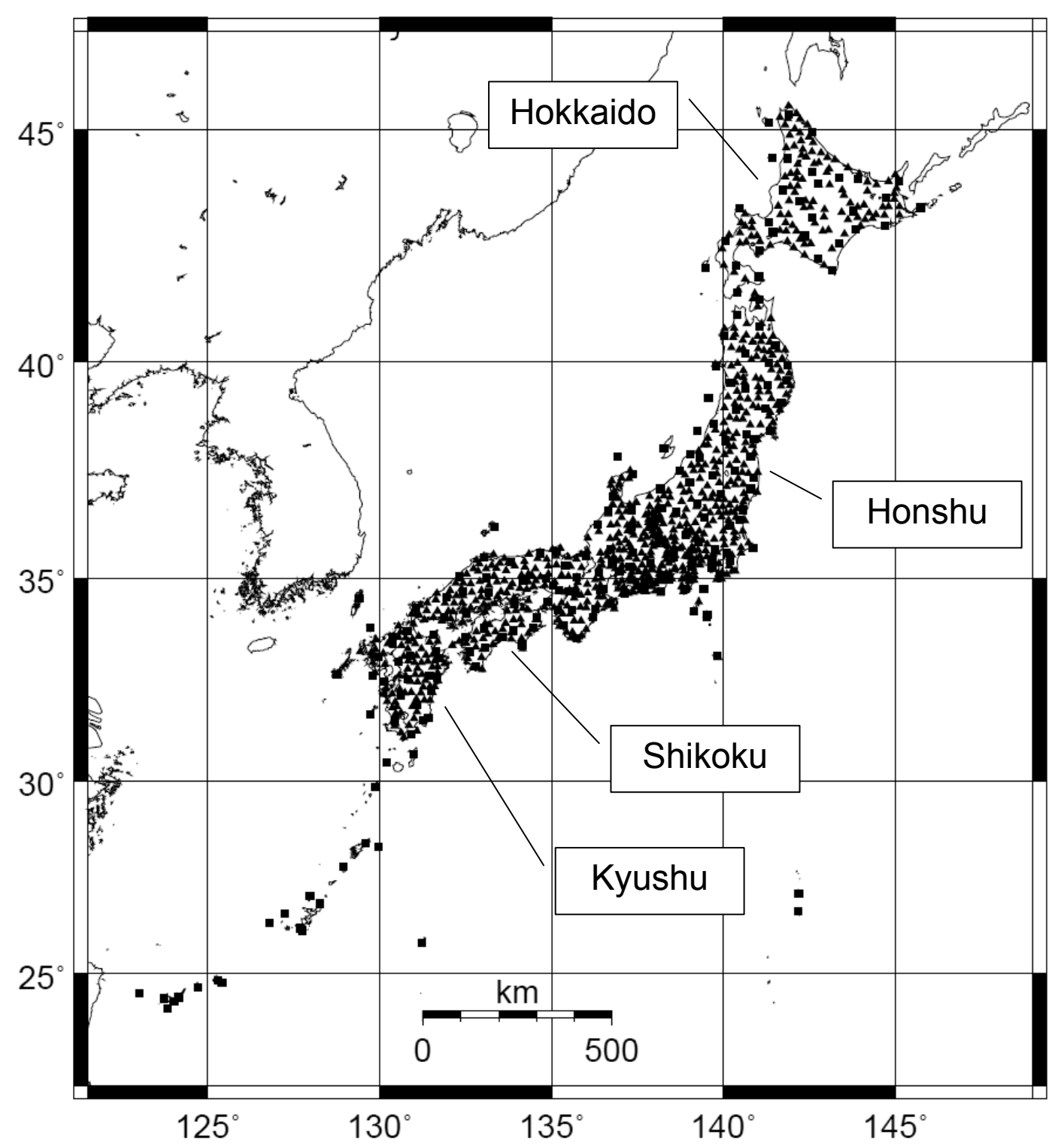

$\Delta$ Figure 1. Seismic station distribution used for EEW.Square denotes a station operated by JMA (about 200), and triangle denotes station operated by NIED (Hi-net, about 800$)$.

fastest possible magnitude estimation, JMA developed a scaling relation between the amplitude of the $P$ phase and magnitude and between the amplitude of the $S$ phase and magnitude. The magnitude-estimation algorithm switches from the $P$ to the $S$ formula at the time of the expected $S$-phase arrival (Kamigaichi 2004).

To minimize the time necessary to estimate the location of the hypocenter, JMA, in cooperation with the Railway Technical Research Institute, has developed a method to estimate epicentral distance and azimuth using the first two seconds of waveform data (Odaka et al. 2003; Tsukada et al. 2004). This is particularly important for events outside the seismic network. JMA also uses several methods for hypocenter location, each optimized to the number of stations available (Kamigaichi 2004). To improve the accuracy, the "not-yetarrived" method developed by the National Research Institute for Earth Science and Disaster Prevention (NIED) is also incorporated (Horiuchi et al. 2005 ; Nakamura et al. 2009). This method makes use of observations that some stations have not yet triggered. In total, about 1,000 seismic stations are used for hypocenter and magnitude calculation for EEW service (Figure 1), 200 installed by JMA originally for tsunami warning and earthquake information services and 800 installed by NIED originally for research purposes. EEW service was realized by fully utilizing pre-existing seismological facilities in Japan.

All EEW systems have a trade-off between speed and accuracy. JMA therefore issues several EEW messages during the course of one earthquake, improving the accuracy of the warning as the amount of available data increases. This allows for both promptness of the first issuance and also accuracy. An index representing the accuracy of hypocenter determination 
is also included in the EEW message to help users choose the optimal time to act depending on what action is planned. The initial warning is issued when the estimated seismic intensity or magnitude exceeds a threshold (at present, 3 for seismic intensity on the JMA scale and 3.5 for magnitude), and when updated hypocenter parameters or seismic intensity estimations give significant changes from the previous ones, then the EEWs are updated. If no other station is triggered in a pre-set time after the initial warning is issued using the first triggered station data, a "cancel report" is issued (Kamigaichi 2004; Hoshiba et al. 2008).

The concept of onsite warning is also incorporated. When the observed acceleration amplitude exceeds $100 \mathrm{~cm} / \mathrm{sec}^{2}$, an initial warning is issued before the first hypocenter calculation is completed. This threshold is roughly equivalent to the JMA's seismic intensity scale 5-lower, which corresponds to the minimum strong motion that will cause damage to buildings.

Computerized warning response systems can utilize a stream of updated information for automatic control. But, when these warnings are transmitted to the general public, it is impossible to respond properly, and moreover, it is impossible to transmit all of the EEW message contents by characters and voice. So, the content and issuance criteria of EEW had to be carefully designed if it was going to be provided to the general public.

\section{PREPARATORY PROCESS TO PROVIDE EEW TO THE GENERAL PUBLIC}

\section{Two-step Process}

On 1 August 2006, JMA started to provide EEW bulletins to a limited number of users who understood the technical limitations of the EEW system (i.e., there exists a near-epicentral area where EEW cannot be provided in a timely manner, seismic intensity estimation has an error of about \pm 1 in JMA scale, etc.) and could utilize it effectively, such as for automatic control of equipment. At that time EEW was not well known to the general public, so JMA began an educational campaign to publicize the EEW concept and the appropriate actions to be taken upon receipt of an EEW message. JMA made leaflets illustrating the proper response to an EEW alert in various situations (http:// www.jma.go.jp/jma/en/Activities/eew.html). JMA also distributed videos explaining the technical principles and proper response and made posters, held seminars, and posted relevant information on EEW on its Web page (http://www.jma.go.jp/). After confirming that the proportion of people who understand EEW had increased significantly by means of these public relations activities, JMA started to provide EEW messages to the general public on the 1 October 2007 (Hoshiba et al. 2008).

\section{Content and Criteria for Issuing EEW Alarms to the General Public}

JMA determined that issuing multiple EEW messages to the general public for one event, i.e., issuing updates, was not feasible, and that an EEW 1) should basically be issued only once, at the optimum time, to avoid false alarms while maintaining as much warning time as possible and minimizing the number of revised warning messages to as few as possible, and 2) should be issued only when and where really strong motion is expected. As a result, a warning is only issued to the general public when the maximum seismic intensity is expected to be 5-lower on the JMA scale (equivalent to VII-VIII on the Modified Mercalli Intensity [MMI] scale) or above and the event has been detected by more than one station. A revised warning is issued when the maximum seismic intensity is anticipated to be equal to 5 -lower or above in a subprefectural area where it was anticipated to be 3 or less in the first issuance.

The EEW message for the general public includes the origin time, epicentral region name, and names of subprefectural areas where seismic intensity 4 or over is expected. Expected arrival time is not included because it differs substantially even in one subprefectural area.

\section{METEOROLOGICAL SERVICE LAW AMENDMENT}

In Japan, not only meteorological but also seismological, volcanological, and oceanographical observation and information provision services for public use are prescribed in the Meteorological Service Law. In addition to the public relations activities described in the Two-step Process section, JMA also amended the Meteorological Service Law to 1) clearly define the issuance and transmission responsibilities of JMA and other relevant organizations to secure prompt transmission of EEW messages to the public, and to 2) establish a technical standard that any warning service providers must satisfy when they issue warnings of expected seismic intensity and arrival time of strong motions to individual houses and buildings. In Japan, provision of expected seismic intensity and $S$-wave arrival time for a specific site is regarded as beyond the duty of the national agency and should be done by other warning service providers.

The technical standard requires that 1) hypocentral parameters (origin time, location, and magnitude) contained in the EEW message issued by JMA must be used, and 2) the seismic intensity and arrival time estimation method used by the service provider must give values within certain deviations from those given by JMA's method. When amplification coefficients of the surface layer are used that are different from JMA's, their technical adequacy must be demonstrated. A method that gives a smaller estimation residual than JMA's is also permitted.

The purpose of this technical standard requirement is not to prohibit use of a superior methodology, but to avoid a lowquality service being provided to the public. Also, this technical standard does not apply to onsite warnings based on $P$-wave sensors at a location. The amended law came into force on the 1 December 2007.

\section{EEW TRANSMISSION AND UTILIZATION}

To ensure the effectiveness of EEW for disaster mitigation, it is very important to establish multiple transmission routes for the prompt delivery of warning information to individuals. Television and radio are currently the main routes. 
NHK (Japan Broadcasting Corporation) is designated by the Meteorological Service Law as the organization that must broadcast EEW alerts. It broadcasts EEW alerts on all of its nine service channels (analog/digital TV and radio). As of September 2008, 122 television companies (out of 127), 34 AM radio companies (out of 47), and 25 FM radio companies (out of 53) broadcast EEW messages to the general public in Japan (in addition to NHK).

The multihazard J-Alert system operated by the Fire and Disaster Management Agency, which uses rapid satellite communication, is another important route to announce EEW messages to the general public through a municipal loud speaker system. As of March 2009, 226 municipalities (out of 1,851 ) have installed J-Alert receivers, but only 102 have started to announce EEW through the loud speaker system.

Two cellular phone companies have started to transmit EEW messages without an additional fee. As of January 2009, the number of the cellular phones in Japan that can receive EEW is 21 million. An additional cellular phone company is developing a similar system.

For automatic control users or for announcement to a specific place (i.e., railway companies, elevator control, factories, construction sites, apartment complexes, schools, shopping malls, hospitals, etc.), a variety of receivers have been developed to receive EEW messages through the Internet or dedicated lines. These EEW messages are provided not only by JMA, but also by other warning service providers. As of March 2009, 54 warning service providers have gotten certificates of JMA's technical standard, and as of December 2008, a total of $126,000 \mathrm{EEW}$ receivers have been sold or are in stores.

Train control is one of the most typical utilizations of EEW in Japan. As of March 2009, 52 railway companies (out of 204) have started to utilize EEW. Some companies are using EEW in combination with independently developed onsite warning systems. Some are using EEW not only for train control, but also to make announcements in the station buildings.

JMA is working closely with the organizations developing and implementing these systems.

\section{SYSTEM PERFORMANCE}

Table 1 shows the earthquakes for which an EEW alarm for the general public was issued and/or a maximum seismic intensity (JMA scale) of 5-lower or above was observed from October 2007 to March 2009. In this period, there were two underestimated alarms, i.e., two events (nos. 1 and 7 ) for which an EEW alert for the general public was not issued but seismic intensity 5-lower was observed, and three overestimated alarms (nos. 2, 6, and 11), i.e., events for which an EEW alert for the general public was issued but the maximum seismic intensity was only 4 .

The $M_{\text {jma }}$ (Katsumata 2004) 7.2 earthquake occurred on 14 June 2008 (Japanese Standard Time) in Iwate Prefecture (Table 1, event no. 4). The maximum seismic intensity observed was 6-upper, and this event caused 23 dead and missing persons, which was the worst in this period. Figure 2(A) and Table 2 show the time histories of epicenter, depth, magnitude, and maximum seismic intensity estimation during the multiple issuances. Figure 2(B) (left) shows observed maximum seismic intensity for each subprefectural area. Seismic intensity on the JMA scale of 5-upper, 6-lower, and 6-upper correspond, approximately, to intensities of VIII-IX, IX-X, and X-XI on the MMI scale, respectively. JMA provided an EEW message to the general public 4.5 seconds after the first detection of the seismic wave. Figure 2(B) (middle) shows the spatial extent of the subprefectural area where seismic intensity 4 or over was expected (shaded area). The concentric circles with numerals denote the available warning time, i.e., the time available for taking action. The warning time is the number of seconds from issuance of the alert to the theoretical $S$-wave arrival. For this event, a revised EEW bulletin for the general public was issued 22.4 seconds after the first detection of the seismic wave (Figure 2B right). The spatial extents of the areas where seismic intensity 4 or greater were observed and estimated are very similar. Although the $S$ wave had already propagated about 30 $\mathrm{km}$ from the epicenter at the time of the first EEW issuance to the general public (corresponds to the circle with numeral "0"), it was in time for other areas where seismic intensity 5 -lower or greater were observed. This earthquake demonstrated that even for an inland event, there are areas where EEW can be utilized when the event is large. It was also the case for the Niigataken Chuetsu-oki earthquake ( $\left.M_{j m a} 6.8\right)$ on 16 July 2007 . At Iizuna-town in Nagano Prefecture, which is about $90 \mathrm{~km}$ from the epicenter, seismic intensity 6-upper was observed and an EEW alert to meet the issuance criteria for the general public was issued 16 seconds before the theoretical S-wave arrival (it was before the commencement of EEW provision to the general public, and EEW messages were transmitted to the limited number of users only).

In this earthquake an electronics company in Miyagi Prefecture stopped supplying chemicals in the factory $12 \mathrm{sec}-$ onds prior to a strong ground motion, and infants at a nursery in Fukushima Prefecture took action to move to the preassigned safety zone in the room 30 seconds before the strong motion arrival. Other utilizations in this event were announcements in factories, offices, schools, and shopping places; elevator control, and manual deceleration of the vehicle.

Figures 3(A) and 3(B) and Table 3 show the example of an earthquake off the coast of Tokachi $\left(M_{j m a} 7.1\right)$ on 11 September 2008 (event no. 10). JMA issued an EEW message to the general public 9.7 seconds after detection of the first seismic wave. The observed and estimated area experiencing seismic intensity 4 or greater (Figure 3B left and right respectively) show good agreement, and the EEW message was prior to the theoretical $S$-wave arrival everywhere in Japan. The 16 August 2006 earthquake off the coast of Miyagi Prefecture $\left(M_{j m a} 7.2\right)$ also had a successful issuance of a warning before the $S$-wave arrival onshore. These events illustrate the effectiveness of EEW for earthquakes in the subduction zone.

There were two cases (Table 1, events nos. 3 and 6), for which it took more than 50 seconds to issue the EEW message to the general public, and it was after the $S$-wave passage in the relevant area. In both cases this was due to the slow growth 


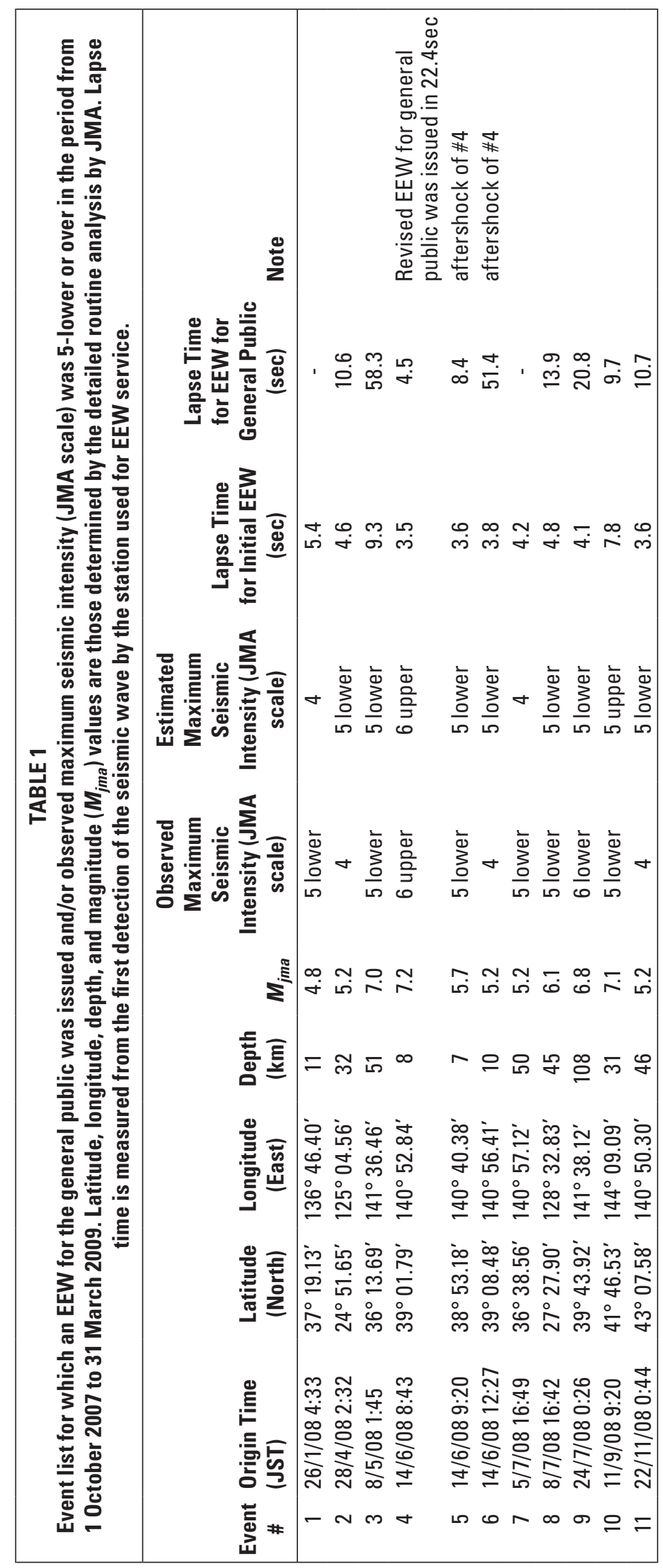




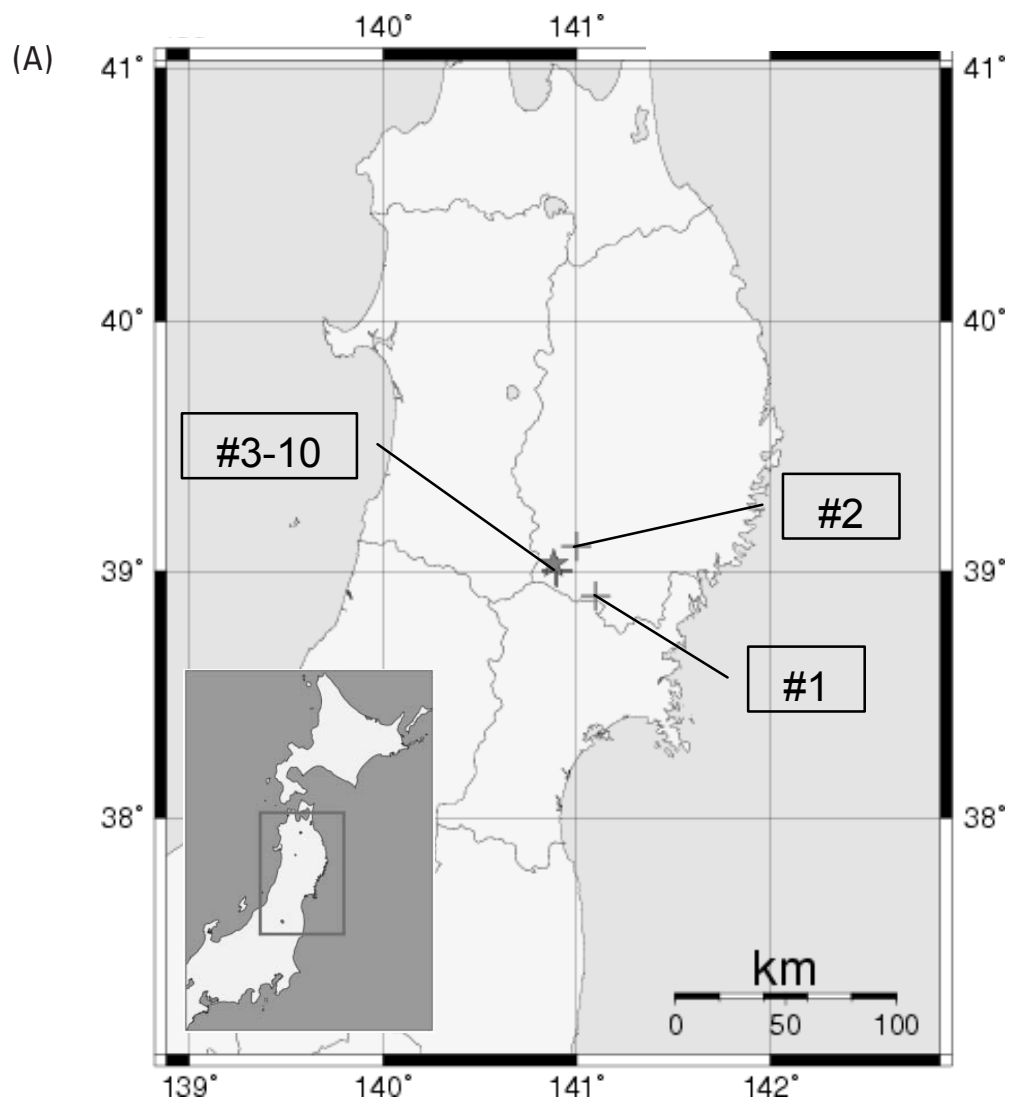

(B) Observed

$1^{\text {st }}$ Warning

$2^{\text {nd }}$ Warning

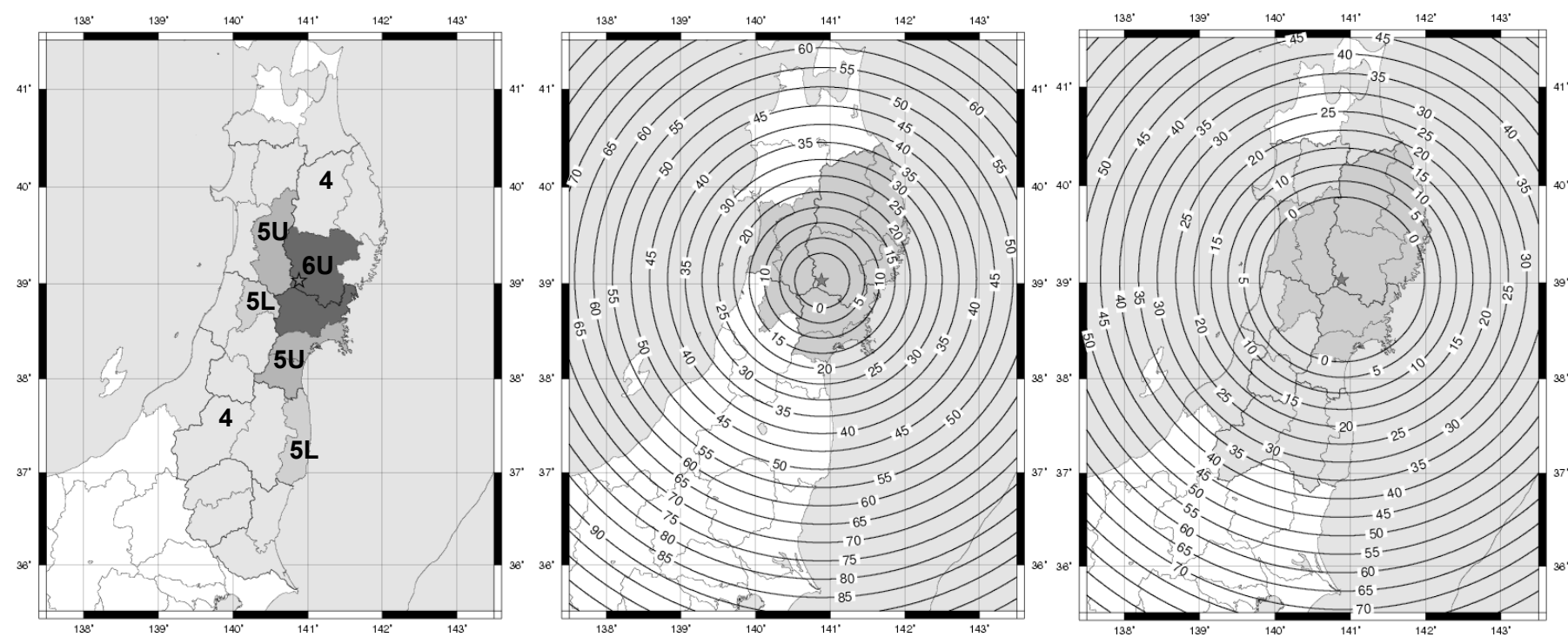

$\Delta$ Figure 2. (A) Time history of estimated epicenter location in each issuance of EEW for the Iwate-Miyagi Nairiku earthquake of 14 June 2008. Dark gray rectangle in the wide area map in the left-bottom corner denotes the map area of the figure. Cross mark and numeral in the box represent the estimated epicenter location and the issuance number in Table 2, respectively. The star denotes the final epicenter determined by the detailed routine analysis of JMA. (B) Observed maximum seismic intensity (JMA scale) in each subprefectural area (left), spatial extent of the subprefectural area in which maximum seismic intensity is expected to be 4 or over in the first EEW (middle) and revised (right) EEW for the general public. Star denotes the final epicenter (same as in Figure 2A). $U$ and $\mathrm{L}=$ upper and lower, respectively. Concentric circles with numerals in the middle and right figures denote contour curves of available time, in seconds, for taking action. 


\begin{tabular}{|c|c|c|c|c|c|c|}
\hline \multicolumn{7}{|c|}{$\begin{array}{l}\text { TABLE } 2 \\
\text { Time history of latitude, longitude, depth, magnitude, and maximum seismic intensity (JMA scale) estimation in each } \\
\text { issuance of EEW for the Iwate-Miyagi Nairiku earthquake on } 14 \text { June 2008. Gray row corresponds to EEW issued for the } \\
\text { general public }\end{array}$} \\
\hline Issuance \# & $\begin{array}{l}\text { Lapse Time } \\
\text { after the First } \\
\text { Seismic Wave } \\
\text { Detection (sec) }\end{array}$ & $\begin{array}{l}\text { Estimated Lat. } \\
\text { (Deg:N) }\end{array}$ & $\begin{array}{l}\text { Estimated Lon. } \\
\text { (Deg:E) }\end{array}$ & $\begin{array}{l}\text { Estimated Depth } \\
\qquad(\mathbf{k m})\end{array}$ & $\begin{array}{l}\text { Estimated } \\
\text { Magnitude }\end{array}$ & $\begin{array}{l}\text { Estimated } \\
\text { Maximum } \\
\text { Seismic } \\
\text { Intensity }\end{array}$ \\
\hline 1 & 3.5 & 38.9 & 141.1 & 10.0 & 5.7 & 5lower \\
\hline 2 & 4.5 & 39.1 & 141.0 & 10.0 & 6.1 & 5upper \\
\hline 3 & 5.4 & 39.0 & 140.9 & 10.0 & 6.2 & 5upper \\
\hline 4 & 6.1 & 39.0 & 140.9 & 10.0 & 6.3 & 5upper \\
\hline 5 & 8.4 & 39.0 & 140.9 & 10.0 & 6.7 & 6upper \\
\hline 6 & 11.4 & 39.0 & 140.9 & 10.0 & 6.7 & 6upper \\
\hline 7 & 22.4 & 39.0 & 140.9 & 10.0 & 6.9 & 6upper \\
\hline 8 & 30.4 & 39.0 & 140.9 & 10.0 & 7.0 & 6upper \\
\hline 9 & 51.4 & 39.0 & 140.9 & 10.0 & 7.0 & 6upper \\
\hline 10 & 62.9 & 39.0 & 140.9 & 10.0 & 7.0 & 6upper \\
\hline
\end{tabular}

of the magnitude. JMA was criticized for poor performance in these events and is currently working to improve its performance. One possible way to prevent such a delayed issuance is to stop issuance if the present time is later than expected $S$-wave arrival times in all subprefectural areas where seismic intensity 5 -lower or over was expected. To judge this, we need to rely on the estimated origin time of the event. But, the present EEW algorithm is incapable of separating two events that are very close in time and space, while even for foreshock-mainshock sequence, JMA needs to issue EEW for damaging mainshock. Therefore, stopping the issuance by judging that the $S$-wave has passed the area relying on the estimated origin time of the foreshock might cause a missed alarm for the damaging mainshock. An event with slow magnitude growth is equivalent to the gradual shift from foreshock to mainshock. JMA therefore needs to consider improvements.

\section{ONGOING SYSTEM DEVELOPMENT AND IMPLEMENTATION}

\section{Promotion of EEW Use}

The ultimate decision about whether to use EEW in public facilities lies with the facility manager. To assist such managers, JMA has developed documentation introducing EEW and providing suggested guidelines on the use of EEW in public places. These include an example of an operations manual and best practices for conducting exercises. These are all available on JMA's Web page (only in Japanese). In addition, JMA personnel actively participate in meetings and discussions of how information can and should be used in public facilities. JMA is collecting "best practices" of EEW utilization in cases of EEW dissemination to the general public, because publicizing these is an effective way to promote EEW utilization.

\section{Improving the Methodology}

\section{Reduction of False Warning}

Out of 1,713 EEWs issued in about three years before the start of the public service, JMA issued 30 false warnings. A "false warning" is defined as any EEW for which a cancel report (see the section "Design of the EEW System") is issued. All of these 30 false warnings were triggered at only one station. By definition, it includes an EEW warning for a real earthquake triggered at only one station. Many of these false warnings were due to human error or initial defects/problems with instruments, which have since been fixed. Still, there exists a possibility of false warning due to a lightning strike near a station, and JMA is developing appropriate countermeasures. Since JMA began providing warnings to a limited number of users in August 2006, nine false warnings were issued as of the end of March 2009. The issuance criteria for the general public is higher in that signals must be detected at more than one station. As a result, no false warning has been issued to the general public.

\section{Improvement of Seismic Intensity Estimation}

JMA has been working on improving the accuracy of the seismic intensity estimation. When the most recent methodology (implemented in October 2007) is applied to events from February 2004 to March 2009 that meet the criteria for general public warning and/or the observed intensity was 5 -lower or more, out of the 456 subprefectural areas where the expected or observed seismic intensity was 4 or above, $24 \%$ have the same maximum seismic intensity as observed and $77 \%$ fall within \pm 1 on the JMA's seismic intensity scale. 
(A)

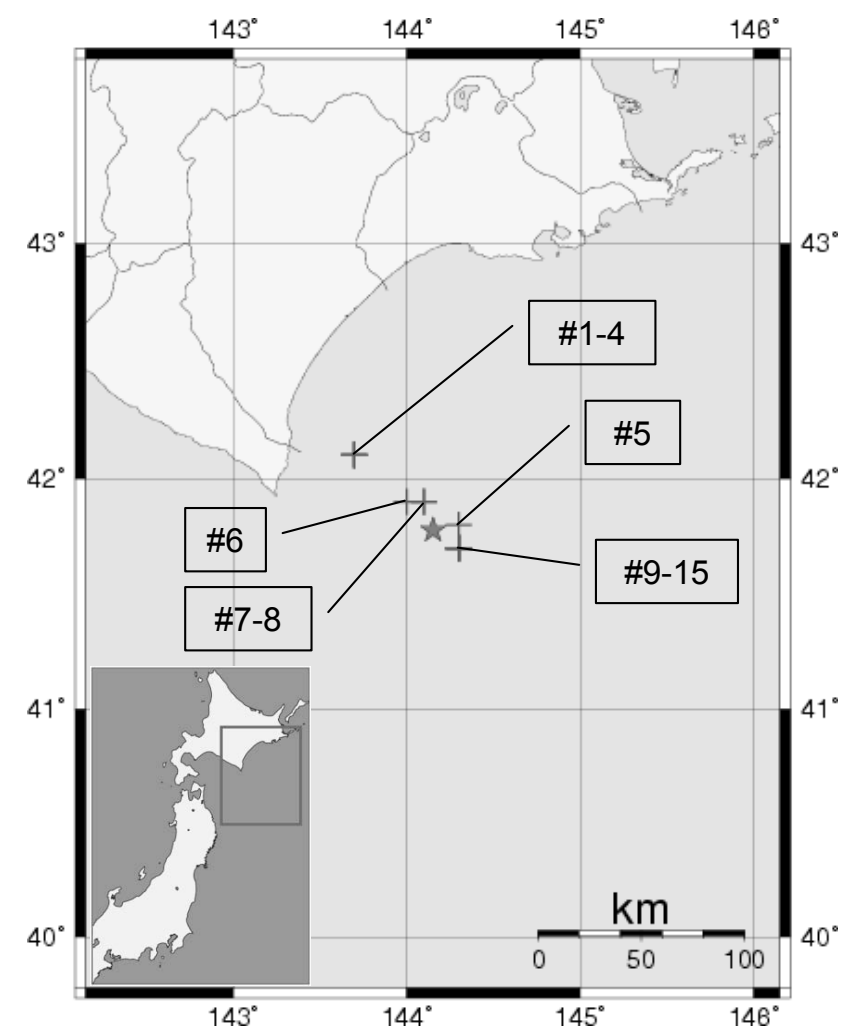

(B)
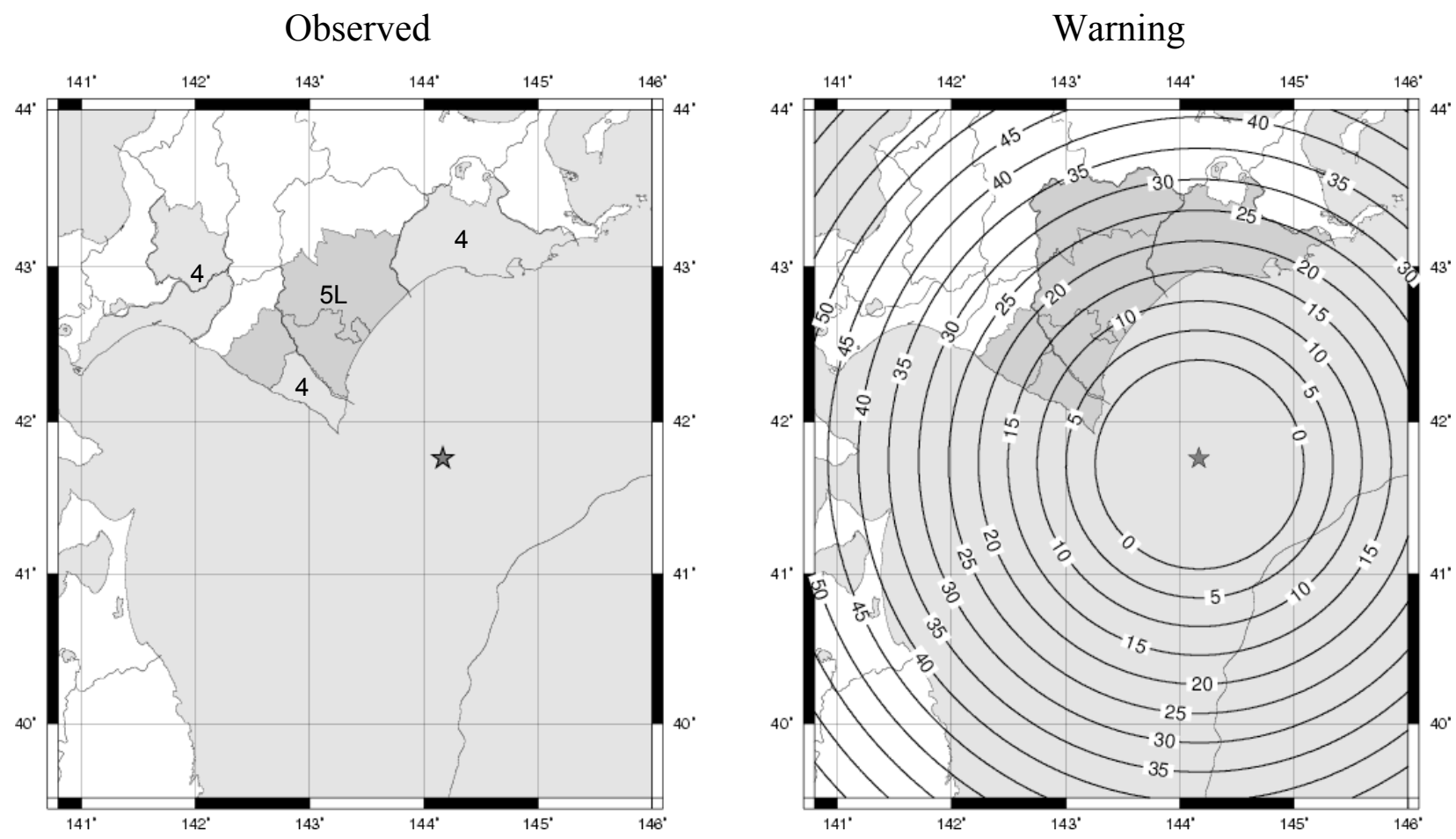

D Figure 3. (A) Time history of estimated epicenter location in each issuance of EEW for the offshore Tokachi coast earthquake on 11 September 2008. Dark gray rectangle in the wide area map in the left-bottom corner denotes the map area of the figure. Cross marks and numerals in the boxes represent the estimated epicenter locations and the issuance numbers in Table 3, respectively. The star denotes the final epicenter determined by the detailed routine analysis of JMA. (B) Observed maximum seismic intensity (JMA scale) in each subprefectural area (left); spatial extent of the subprefectural area in which maximum seismic intensity is expected to be 4 or over in the EEW for the general public (right). Star denotes the final epicenter (same as in Figure 3A). $\mathrm{U}$ and $\mathrm{L}=$ upper and lower, respectively. Concentric circles with numerals in the right figure denote contour curves of available time, in seconds, for taking action. 


\begin{tabular}{|c|c|c|c|c|c|c|}
\hline \multicolumn{7}{|c|}{$\begin{array}{c}\text { TABLE } 3 \\
\text { Same as Table } 2 \text { for the Offshore Tokachi Coast Earthquake on } 11 \text { September } 2008 .\end{array}$} \\
\hline Issuance \# & $\begin{array}{l}\text { Lapse Time } \\
\text { after the First } \\
\text { Seismic Wave } \\
\text { Detection (sec) }\end{array}$ & $\begin{array}{l}\text { Estimated Lat. } \\
\text { (deg:N) }\end{array}$ & $\begin{array}{l}\text { Estimated Lon. } \\
\text { (deg:E) }\end{array}$ & $\begin{array}{l}\text { Estimated Depth } \\
\quad(\mathbf{k m})\end{array}$ & $\begin{array}{l}\text { Estimated } \\
\text { Magnitude }\end{array}$ & $\begin{array}{c}\text { Estimated } \\
\text { Maximum } \\
\text { Seismic } \\
\text { Intensity }\end{array}$ \\
\hline 1 & 7.8 & 42.1 & 143.7 & 10.0 & 5.7 & 4 \\
\hline 2 & 8.7 & 42.1 & 143.7 & 10.0 & 6.1 & 4 \\
\hline 3 & 9.7 & 42.1 & 143.7 & 10.0 & 6.5 & 5lower \\
\hline 4 & 11.3 & 42.1 & 143.7 & 10.0 & 6.4 & 5lower \\
\hline 5 & 12.2 & 41.8 & 144.3 & 30.0 & 7.0 & 4 \\
\hline 6 & 12.8 & 41.9 & 144.0 & 90.0 & 6.9 & 5lower \\
\hline 7 & 18.2 & 41.9 & 144.1 & 50.0 & 7.2 & 5lower \\
\hline 8 & 22.6 & 41.9 & 144.1 & 10.0 & 7.2 & 5lower \\
\hline 9 & 30.3 & 41.7 & 144.3 & 10.0 & 7.3 & 5lower \\
\hline 10 & 31.5 & 41.7 & 144.3 & 50.0 & 7.5 & 5upper \\
\hline 11 & 35.3 & 41.7 & 144.3 & 50.0 & 7.5 & 5upper \\
\hline 12 & 56.3 & 41.7 & 144.3 & 50.0 & 7.4 & 5lower \\
\hline 13 & 77.3 & 41.7 & 144.3 & 50.0 & 7.4 & 5lower \\
\hline 14 & 98.4 & 41.7 & 144.3 & 50.0 & 7.4 & 5lower \\
\hline 15 & 107.3 & 41.7 & 144.3 & 50.0 & 7.4 & 5lower \\
\hline
\end{tabular}

\section{FUTURE PLANNED DEVELOPMENT}

\section{Rapid Estimation of the Spatial Extent of Rupture}

The regression formula currently used for the estimation of maximum velocity amplitude requires the minimum distance to the fault surface (Si and Midorikawa 1999). The warning system uses the distance from a hypothetical sphere centered at the hypocenter and with a radius given by a scaling law between magnitude and typical fault length (Utsu et al. 2001). This is because it is difficult to estimate fault geometry and spatial extent in a prompt manner. JMA plans to improve the system by rapidly estimating the fault geometry and extent (e.g., Yamada et al. 2007; Yamamoto et al. 2008), thereby improving the accuracy of the seismic intensity estimation.

\section{Reduction of the Area in Which EEW Cannot Be Provided in a Timely Manner}

In order to reduce the size of the region close to the epicenter where strong motion occurs before a warning is received, JMA is increasing the number of available strong motion instruments. In addition, improvement of the onsite warning algorithm (e.g., Wu and Kanamori 2005) would be helpful.

\section{Incorporation of Three-dimensional Tectonic Structure}

The present maximum velocity amplitude estimation formula ( $\mathrm{Si}$ and Midorikawa 1999) is for the averaged attenuation structure and stress drop amount in and around Japan. Due to very complicated crustal structure and/or the existence of the subducting plate, seismic intensity distribution can change for the same magnitude events depending on the region and whether the earthquake is an inter- or an intra-plate event. To improve seismic intensity estimation accuracy, it is necessary to incorporate three-dimensional structure (Kanda 2007; Wu et al. 2006).

\section{Application for Different Frequency Bands}

Seismic intensity estimated in EEW represents the ground motion strength in the 0.5 to $10 \mathrm{~Hz}$ frequency band. The existence of high-rise buildings, which are affected by very long period oscillation that cannot be covered by the present seismic intensity estimation, is increasing. To predict damages to such huge structures, it will be necessary to incorporate the longperiod ground-motion estimation method (Kubo et al. 2009; Yamamoto and Horiuchi 2009).

\section{CONCLUSIONS}

1. JMA's Earthquake Early Warning (EEW) system is designed to enable public officials, key safety personnel and the general public to take advance countermeasures against the strong motion effects caused by earthquakes by providing estimated seismic intensity (JMA scale) and arrival time of the strong motion before it arrives. Considering the inevitable trade-off between speed and accuracy and the variety of requirements depending on what actions are planned, EEW messages are issued several times during the course of one earthquake.

2. To make EEW effective not only for the users for automatic control but also for the general public, JMA conducted a nationwide campaign to publicize the purpose and technical nature of EEW and proper responses when it is received. JMA also determined the message contents and issuance 
criteria of EEW alerts to the general public. After these steps, JMA started to provide EEW alerts for the general public on October 1, 2007. In addition, JMA determined technical standards that third-party warning service providers must satisfy if they are going to issue expected seismic intensities and arrival times at specific sites.

3. To ensure EEW's effectiveness in disaster mitigation, JMA is working with relevant organizations to establish multiple transmission routes for the prompt delivery of warning information to individuals. Currently, TV and radio are the main routes. In addition, cellular phones that can receive EEW messages, receivers designed specifically for EEW that get their information through the Internet or via dedicated lines, and loud speaker systems connected to the rapid satellite communication system are being developed and implemented.

4. The Iwate-Miyagi Nairiku earthquake on 14 June 2008 $\left(M_{j m a} 7.2\right)$, the severest earthquake disaster after the commencement of EEW provision to the general public, revealed the inherent technical limitations of EEW in that warnings cannot be provided in a timely manner in the near-epicentral area. At the same time, it demonstrated that even for an inland event, there are areas where EEW can be utilized if the earthquake is large enough. The offshore Tokachi coast earthquake on 11 September 2008 $\left(M_{j m a} 7.1\right)$ demonstrated the effectiveness of EEW for subduction events. $\mathbb{<}$

\section{ACKNOWLEDGMENTS}

Discussion with Dr. Richard Allen was very important in improving this manuscript. We thank an anonymous reviewer for his helpful comments.

\section{REFERENCES}

Horiuchi, S., H. Negishi, K. Abe, A. Kamimura, and Y. Fujinawa (2005). An automatic processing system for broadcasting earthquake alarms. Bulletin of the Seismological Society of America 95, 708-718.

Hoshiba, M., O. Kamigaichi, M. Saito, S. Tsukada, and N. Hamada (2008). Earthquake early warning starts nationwide in Japan.EOS, Transactions, American Geophysical Union 89 (8), 73-80.

Iio, Y., S. Ohmi, R. Ikeda, E. Yamamoto, H. Ito, H. Sato, Y. Kuwahara, T. Ohminato, B. Shibazaki, and M. Ando (1999). Slow initial phase generated by micro-earthquakes occurring in the western Nagano Prefecture, Japan-the source effect. Geophysical Research Letters 26, 1,969-1,972.

JMA (1996). Seismic Intensity. Tokyo: Gyosei, 238 pps. (in Japanese).

Kamigaichi, O. (2004). JMA earthquake early warning. Journal of the Japan Association for Earthquake Engineering 4, 134137.

Kanda, K. (2007). Seismic intensity evaluation considering wave propagation characteristics based on observed data. In Proceedings of the Symposium on the Promotion of Seismic Intensity Meter Installation and Sophisticated Utilization of Seismic Intensity Data, 46-51 (in Japanese).

Katsumata, A. (2004). Revision of the JMA displacement magnitude. Quarterly Journal of Seismology 67, 1-10 (in Japanese).
Kubo, T., H. Hisada, S. Horiuchi, and S. Yamamoto (2009). Application of long-period ground motion prediction using earthquake early warning system to elevator emergency operation control system of a high-rise building. Journal of Japan Association for Earthquake Engineering 9 (2), 31-50 (in Japanese).

Matsuoka, M., and S. Midorikawa (1994). Digital national land information and seismic microzoning. In Proceedings of the 22nd Symposium of Earthquake Ground Motion, Architectural Institute of Japan, 23-34 (in Japanese).

Midorikawa, S., K. Fujimoto, and I. Muramatsu (1999). Correlation of new JMA instrumental seismic intensity with former JMA seismic intensity and ground motion parameters. Journal of the Institute of Social Safety Science 1, 51-56 (in Japanese).

Mori, J., and H. Kanamori (1996). Initial rupture of earthquake in the 1995 Ridgecrest, California sequence. Geophysical Research Letters 23, 2,437-2,440.

Nakamura, H., S. Horiuchi, C. Wu, S. Yamamoto and P. A. Rydelek (2009), Evaluation of the real-time earthquake information system in Japan. Geophysical Research Letters 36; doi:10.1029/2008GL036470.

Nakatani, M., S. Kaneshima, and Y. Fukao (2000). Size dependent microearthquake initiation inferred from high-gain and low noise observations at Nikko district, Japan. Journal of Geophysical Research 105, 28,095-28,109.

Odaka, T., K. Ashiya, S. Tsukada, S. Sato, K. Ohtake, and D. Nozaka (2003). A new method of quickly estimating epicentral distance and magnitude from a single seismic record. Bulletin of the Seismological Society of America 93, 526-532.

Si, H., and S. Midorikawa (1999). Attenuation relationships of peak ground acceleration and velocity considering effects of fault type and site condition. Architectural Institute of Japan Journal of Structural and Construction Engineering 523, 63-70 (in Japanese).

Tsukada, S., T. Odaka, K. Ashiya, K. Ohtake, and D. Nozaka (2004). Analysis of the envelope waveform of the initial part of p-waves and its application to quickly estimating the epicentral distance and magnitude. Jishin2 56 (4), 351-361 (in Japanese).

Utsu, T., E. Shima, T. Yoshii, and K. Yamashina (2001). Encyclopedia of Earthquakes. 2nd ed. Tokyo: Asakura, 657 pps (in Japanese).

Wu, C., S. Horiuchi, and S. Yamamoto (2006). Improving the real-time prediction of shaking intensities using a 3-dimensional Q model beneath the Japan islands. Program and Abstracts, The 2006 Fall Meeting of the Seismological Society of Japan Tokyo: Seismological Sociery of Japan, D024.

Wu, Y. M., and H. Kanamori (2005). Experiment on an onsite early warning method for the Taiwan early warning system. Bulletin of the Seismological Society of America 95, 347-353.

Yamada, M., T. Heaton, and J. Beck (2007). Real-time estimation of fault rupture extent using near-source versus far-source classification. Bulletin of the Seismological Society of America 97 (6), 1,890-1,910.

Yamamoto, S., K. Ashiya, S. Sato, M. Korenaga, K. Irikura, and Y. Fukushima (2008). Real-time imaging of asperities and estimating seismic intensity of large earthquakes. Program and Abstracts, The $7^{\text {th }}$ General Assembly of the Asian Seismological Commission and the 2008 Fall Meeting of the Seismological Society of Japan Tokyo: Seismological Society of Japan, A32-04.

Yamamoto, S., and S. Horiuchi (2009). Potential of frequency-response magnitude for earthquake early warning. Journal of Japan Association for Earthquake Engineering 9 (2), 17-30 (in Japanese).

Japan Meteorological Agency 1-3-4, Ohte-machi, Chiyoda-ku Tokyo, Japan okamigai@met.kishou.go.jp 